\title{
SINTOMAS OSTEOMUSCULARES EM PROFESSORES DO ENSINO FUNDAMENTAL
}

\author{
Carvalho AJFP ${ }^{1}$, Alexandre NMC ${ }^{2}$ \\ ${ }^{1}$ Centro Universitário das Faculdades Associadas de Ensino, São João da Boa Vista, SP \\ 2 Universidade Estadual de Campinas, Campinas, SP \\ Correspondência para: Ana Júlia Frazão Panzeri de Carvalho, Rua João Goulart 160, Parque das Nações, CEP 13870-000, \\ São João da Boa Vista, SP, e-mail: ajfpcarvalho@ig.com.br
}

Recebido: 13/10/2004 - Aceito: 18/08/2005

\begin{abstract}
RESUMO
Objetivo: Identificar a ocorrência de sintomas osteomusculares em professores do Ensino Fundamental. Método: Foi utilizado um questionário com um inventário sobre dados gerais e ocupacionais e o Questionário Nórdico. Para a análise estatística foram comparados os sujeitos com e sem sintomas nos últimos 12 meses, independente da região e considerando as mais afetadas. Foi realizada análise de regressão logística univariada e multivariada com um nível de significância de 5\%. Para a análise multivariada, foi utilizado o critério Stepwise. As variáveis foram analisadas pelo teste de associação Qui-Quadrado ou teste de Fisher. Resultados: A idade média dos participantes foi de 40 anos, 99,4\% eram mulheres, sendo que, 90,4\% apresentaram sintomas osteomusculares. As áreas mais atingidas foram: lombar, torácica, cervical, ombros, punhos e mãos. A presença de dor associou-se significativamente com a ausência de filhos $(\mathrm{p}=0,03)$ e com o tempo de atuação profissional menor ou igual a 15 anos $(\mathrm{p}=0,03)$. Na análise multivariada, a presença de dor na região cervical $(\mathrm{OR}=6,2$, IC à 95\% $=1,4-26,7)$, nos ombros $(\mathrm{OR}$ $=2,8$, IC à $95 \%=1,1-7,2)$, na região torácica $(\mathrm{OR}=2,5$, IC à $95 \%=1,1-5,5)$ e punhos e mãos $(\mathrm{OR}=2,0, \mathrm{IC}$ à $95 \%=1,0-3,9)$ apresentou associação significativa para a idade menor que 30 anos, sujeitos entre 30 e 39 anos, ausência de filhos e não ter uma união estável, respectivamente. Conclusão: Os professores apresentaram elevada ocorrência de sintomas osteomusculares e confirmam a necessidade de novos estudos.
\end{abstract}

Palavras-chave: sintomas osteomusculares, professores, ergonomia, fisioterapia.

\section{ABSTRACT \\ Musculoskeletal Symptoms in Elementary School Teachers}

Objective: To identify the occurrence of musculoskeletal symptoms in elementary school teachers. Method: A questionnaire containing an inventory for general and occupational data and the Nordic questionnaire were utilized. In the statistical analysis, subjects with and without symptoms over the last 12 months were compared for statistical analysis, independent of the symptom region and degree of severity. Univariate and multivariate logistic regression analysis was performed using a significance level of $5 \%$. The stepwise criterion was utilized for the multivariate analysis. The variables were analyzed using the chi-squared test of association or Fisher's test. Results: The participants' average age was 40 years; $99.4 \%$ were women and $90.4 \%$ of them presented musculoskeletal symptoms. The regions most affected were: lower back, chest, neck, shoulders, wrists and hands. The presence of pain was significantly associated with absence of children $(p=0.03)$ and duration of professional activities shorter than or equal to 15 years $(\mathrm{p}=0.03)$. In the multivariate analysis, the presence of pain in the neck region (odds ratio $(\mathrm{OR})$ : 6.2; 95\% confidence interval (CI): 1.4-26.7), shoulders (OR: 2.8; 95\% CI: 1.1-7.2), chest (OR: 2.5; 95\% CI: 1.1-5.5) and wrists and hands (OR: 2.0; 95\% CI: 1.0-3.9) presented significant associations with age less than 30 years, age 30-39 years, absence of children and absence of a stable relationship, respectively. Conclusion: Teachers presented high occurrence of musculoskeletal symptoms and this confirms the need for further studies.

Key words: musculoskeletal symptoms, teachers, ergonomics, physical therapy. 


\section{INTRODUÇÃO}

Os distúrbios do sistema musculoesquelético têm despertado a atenção de pesquisadores preocupados com questões relativas à saúde e ao trabalho devido o custo e o impacto na qualidade de vida ${ }^{1}$. Esses distúrbios incluem várias doenças articulares, problemas de coluna, distúrbios em tecidos moles, condições ósseas e trauma de difícil avaliação clínica ${ }^{2}$. Considerando-se a utilização do questionário Nórdico como referencial teórico, optou-se por definir sintomas osteomusculares como o "auto-relato de dor, formigamento ou dormência em nove diferentes regiões corporais”3.

De acordo com National lnstitute for Ocupational Safety and Health ${ }^{4}$ e Yeng et al. ${ }^{5}$, os distúrbios osteomusculares relacionados ao trabalho nos Estados Unidos da América, foram os componentes de maior custo econômico, destacando-se de outras doenças ocupacionais. Nos anos 80 , os sintomas osteomusculares começaram a se destacar no Brasil, tornando-se um grande problema de saúde pública ${ }^{6}$. Decorrem das solicitações do aparelho locomotor durante a execução das atividades da vida diária e ocupacional e eventos traumáticos, podendo desencadear dor, incapacidade funcional e sofrimento físico e psicoafetivo ${ }^{7}$. Estudos confirmam que os sintomas musculoesqueléticos se desenvolvem por caracteres multifatoriais, destacando-se os fatores biomecânicos presentes na atividade, fatores psicossociais, características individuais e os fatores ocupacionais ${ }^{6,8,9}$.

No Brasil, pouco ainda tem sido feito para avaliar a repercussão do trabalho sobre a saúde em categorias de trabalhadores em que os fatores de risco são menos visíveis, como por exemplo, os professores. Para Alexander ${ }^{10}$, escola é uma "indústria complexa" que envolve diversas atividades que potencializam a ocorrência de problemas de saúde. Atualmente, há na literatura internacional e nacional uma escassez de estudos específicos sobre sintomas osteomusculares na categoria. Dentro deste contexto, este estudo, tem como objetivos: identificar os sintomas musculoesqueléticos, sua ocorrência (semanal e anual), suas repercussões funcionais e a necessidade de atendimento por algum profissional da área da saúde em professores do Ensino Fundamental.

\section{METODOLOGIA}

\section{Campo da pesquisa}

Foram pesquisados professores que se distribuem pelas 18 escolas da Rede Pública do Ensino Fundamental, de uma cidade do interior do Estado de São Paulo. A rede de ensino é constituída de um total de 20 escolas sendo que a diretoria de duas não autorizou a realização da pesquisa.

\section{Sujeitos}

Os sujeitos do estudo foram os professores municipais e estaduais do Ensino Fundamental. Como critério de inclusão considerou-se todos os professores efetivos, ativos no período da coleta de dados e que estavam trabalhando em salas de aula, diretamente com os alunos. Foram excluídos os professores em algum tipo de afastamento ou licença no período da coleta dos dados, que realizavam atividades administrativas, e aqueles que não concordaram em participar do estudo.

\section{Coleta de dados}

A coleta de dados foi realizada por uma das autoras. Foi solicitado autorização para a realização da pesquisa junto às redes estaduais e municipais. Solicitou-se também uma lista dos professores pertencentes a cada escola, com suas respectivas funções. Nas escolas estaduais, foram entregues os questionários aos professores nos intervalos das aulas, explicando os objetivos do estudo e concedendo-lhes um prazo de uma semana para o preenchimento. Quanto às escolas municipais, o questionário foi entregue durante as reuniões semanais que ocorre no Departamento de Educação. Durante o período de preenchimento, uma das autoras colocou-se à disposição para o esclarecimento de dúvidas que podiam surgir. Para sigilo da identificação profissional, cada questionário obteve uma numeração. Foi desenvolvida uma listagem com o número correspondente a cada professor e a cada escola. A participação na pesquisa foi voluntária, de forma que o não preenchimento do questionário significou a não concordância em participar da pesquisa.

\section{Instrumentos de coleta de dados}

Utilizou-se como instrumento, a aplicação de um questionário auto-aplicável com duas partes:

\section{a) Dados gerais e ocupacionais}

Esta parte foi desenvolvida tendo outras pesquisas como suporte teórico ${ }^{11,12}$. O instrumento construído foi submetido à validação de seu conteúdo por meio da apreciação de seis juízes com reconhecido saber na temática investigada. Três juízes eram docentes do Departamento de Medicina Preventiva e Social, um do Departamento de Enfermagem e, uma socióloga do Centro de Pesquisas Materno-Infantil de Campinas (Cemicamp), todos da Universidade Estadual de Campinas (Unicamp) e, também, um docente do Ensino Fundamental da rede estadual. Foi aplicado também um préteste a 26 professores que não participaram da pesquisa. Houve mudanças em algumas questões onde o critério utilizado foi um (1) professor ter considerado a questão inadequada. $\mathrm{O}$ instrumento foi então, corrigido e adaptado obtendo, assim, uma versão final.

\section{b) Questionário Nórdico}

Para avaliar os sintomas musculoesqueléticos, foi utilizada a parte geral do Questionário Nórdico. Esse 
instrumento foi adaptado culturalmente para a língua portuguesa por Barros e Alexandre ${ }^{3}$ em 2003, apresentando uma confiabilidade variando de 0,88 a 1 segundo o coeficiente de Kappa. É formado por uma figura humana dividida em nove regiões anatômicas. Compreende também, questões quanto à presença de dores musculoesqueléticas anual e semanal, se houve incapacidade funcional e se houve procura por algum profissional da área da saúde nos últimos 12 meses.

\section{Análise dos dados}

Realizou-se inicialmente uma análise descritiva dos dados, através do uso de tabelas de freqüência para as variáveis categóricas e estatísticas descritivas (média e desvio-padrão) para as variáveis numéricas. Para a análise estatística foram comparados os sujeitos, com e sem sintomas nos últimos 12 meses (sim/não), independente da região corporal afetada e posteriormente considerando as diferentes áreas corporais (região cervical, ombros, região torácica, cotovelos, punhos/ mãos, região lombar, quadril/coxas, joelhos, tornozelos/pés). Foi realizada análise de regressão logística univariada e em seguida, multivariada com um nível de significância de 5\%. Quanto à análise multivariada, foi utilizado o critério Stepwise para seleção das variáveis mais significativas ${ }^{13}$, o que permitiu a seleção de uma ou mais variáveis associadas conjuntamente com a variável resposta dor. As relações entre as variáveis categóricas foram analisadas pelos testes de associação QuiQuadrado ou teste exato de Fisher (para valores esperados menores que 5).

\section{Categorização das variáveis}

Para realizar a análise estatística foram consideradas as seguintes variáveis:

- idade: menor que 30 anos, 30 a 39, 40 a 49 e 50 ou mais anos;

• estado marital: ter e não uma união estável;

- filhos: ausência e presença de filhos;

- realização de atividade física: sim e não;

- rede de ensino que leciona: um e dois ou mais locais;

- número de classes que leciona: uma e duas ou mais classes;

- número de alunos por sala de aula: menos que 35 e

35 ou mais alunos;

• tempo de atuação na profissão: tempo menor ou igual a 15 anos e maior que 15;

- carga horária semanal: menor que 40 e 40 ou mais horas;

- rendimento médio pessoal: menor ou igual a seis e maior que seis salários-mínimos.

Outros fatores não foram considerados por não apresentarem relevâncias significativas.

\section{Aspectos éticos}

O projeto obteve o parecer favorável da Comissão de Ética em Pesquisa da Faculdade de Ciências Médicas da
Universidade Estadual de Campinas - Unicamp, sob parecer $n^{0} 528 / 2002$. Os participantes foram informados sobre a pesquisa e assinaram o Termo de Consentimento Livre e Esclarecido (TCLE).

\section{RESULTADOS}

Dos duzentos e doze professores, cento e cinqüenta e sete responderam ao questionário auto-aplicado representando uma taxa de participação de 74,1\%. Em relação aos professores que não responderam, verificou-se que todos eram do sexo feminino e estavam distribuídos igualitariamente entre as diversas escolas participantes. Não houve justificativa da não participação.

\section{Dados gerais e ocupacionais}

A média de idade dos participantes foi de 40 anos (DP $\pm 9,01$ ), 99,4\% eram do sexo feminino, sendo que $67,5 \%$ do total vivem uma união estável. Em relação à escolaridade, 91,1\% possuíam ensino superior completo. Dos participantes $53,5 \%$ realizavam atividade física, sendo a caminhada a prática mais referida (66,7\%). Dos professores, 56,1\%, lecionavam na Rede Estadual de Ensino, 24,8\% na Rede Municipal e 19\% em 2 ou 3 redes de ensino, inclusive a rede particular. $\mathrm{O}$ número médio de classes em que ministravam aulas foi de 3,52 (DP $\pm 4,79$ ) e a média do número de alunos por sala foi de 32,6 alunos ( $\mathrm{DP} \pm 6,58$ ). A lousa foi o material didáticopedagógico utilizado por mais tempo $(99,4 \%)$. Os professores, desta amostra, atuam na profissão há um tempo médio de 16,4 anos (DP \pm 6,82) com carga horária semanal média de 34,6 horas (DP $\pm 9,61$ ). Do total de participantes, $5,7 \%$ referiu realizar outra atividade ocupacional remunerada diferente de professor. Em relação à renda individual mensal dos professores estudados constatou-se que a maioria $(73,2 \%)$ possui rendimento de 4 a 6 salários-mínimos (SM).

\section{Sintomas musculoesqueléticos}

No que se refere à ocorrência anual e semanal de sintomas musculoesqueléticos, verificou-se que dos cento e cinqüenta e sete participantes, 90,4\% apresentaram sintomas nos últimos 12 meses e 64,3\%, nos últimos sete dias.

Nos últimos 12 meses, os professores apresentaram ocorrência maior de sintomas osteomusculares principalmente nas regiões lombar $(63,1 \%)$, torácica $(62,4 \%)$, cervical (59,2\%), ombros $(58,0 \%)$ e punhos e mãos $(43,9 \%)$. Em relação à prevalência nos últimos 7 dias, as áreas corporais mais citadas foram ombros (29,9\%), cervical (28,7\%), lombar $(27,4 \%)$, torácica $(27,4 \%)$ e punhos e mãos $(14,6 \%)$ (Figura 1).

As regiões que mostraram maior porcentagem de 


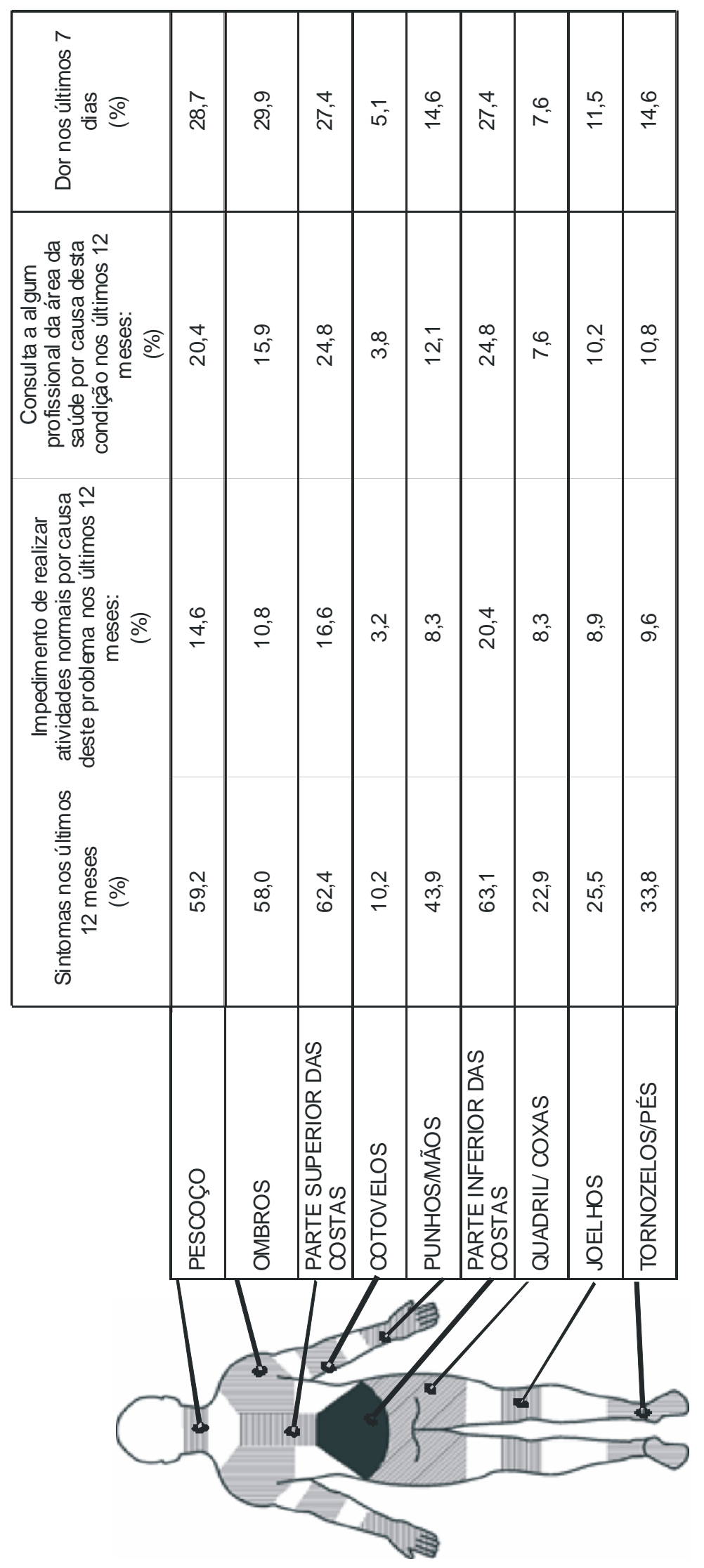


queixas para incapacidade funcional foram a região lombar (20,4\%), torácica $(16,6 \%)$, cervical $(14,6 \%)$, ombros $(10,8 \%)$ e tornozelos e pés $(9,6 \%)$. Em relação às regiões mais citadas quanto à procura por algum profissional da área da saúde nos últimos 12 meses destacaram-se a região lombar e torácica respectivamente (24,8\%), cervical (20,4\%), ombros (15,9\%) , punhos e mãos (12,1\%) (Figura 1).

\section{Fatores de risco}

Inicialmente, para avaliar os fatores de risco, dividiramse os sujeitos com e sem dor musculoesquelética nos últimos 12 meses independentemente da região corporal afetada. Por meio da análise univariada, constatou-se que a presença de dor osteomuscular associou-se significativamente com a ausência de filhos ( $p=0,03$ ) e com o tempo de atuação profissional inferior ou igual a 15 anos $(\mathrm{p}=0,03)$. Pela análise multivariada, constatou-se que a chance de apresentar sintomas musculoesqueléticos mostrou também associação significativa com o tempo de atuação profissional inferior ou igual a 15 anos $(\mathrm{OR}=3,7$, IC à 95\% = 1,01 - 13,7).

Ao realizar a análise por área corporal, a região torácica apresentou diferença significativa para a ausência de filhos $(p=0,01)$. A presença de dor osteomuscular em região de punhos e mãos apresentou associação significativa com a atuação do professor em mais de uma rede de ensino $(\mathrm{p}=$ 0,04). com a ausência de filhos (OR = 2,5, IC à 95\% = 1,1 - 5,5). A região de punhos e mãos apresentou diferença significativa em não ter uma união estável (OR = 2,0, IC à 95\% = 1,0 3,9) (Tabela 1).

\section{DISCUSSÃO}

A média de idade dos professores foi de 40,3 anos e o sexo feminino foi predominante, sendo que mais da metade vivia uma união estável. Quanto ao grau de escolaridade, a maioria dos sujeitos possui nível superior completo e a minoria, alguma especialidade. Este fato se deve ao surgimento da Lei de Diretrizes e Bases da Educação Nacional (LDB), Lei 9.394/ 96, Art 62, que passou a exigir escolaridade superior a todos os professores para o ensino básico (ensino fundamental e ensino médio) $)^{14}$.

Em relação à prática de atividade física, percebeu-se que mais da metade dos participantes realiza exercícios físicos sendo a caminhada a mais praticada. No entanto, destacase que 46,5\% dos professores não realizam atividade física, o que pode ser explicado pela falta de tempo, dupla jornada de trabalho ou por questões socioeconômicas.

Quanto à rede de ensino que os professores lecionavam, verificou-se que $19 \%$ dos sujeitos lecionavam em duas ou três instituições, incluindo a rede particular. Desse modo, estão

Tabela 1. Análise multivariada para associação das variáveis com sintomas musculoesqueléticos por região corporal, São João da Boa Vista, 2003.

\begin{tabular}{|c|c|c|c|}
\hline $\begin{array}{l}\text { Sintomas } \\
\text { musculoesquelét }\end{array}$ & Variáveis & OR (IC 95\%) & $\mathrm{p}$ \\
\hline cervical & idade $<30 \operatorname{anos}^{(\bullet)}$ & $6,2(1,4-26,7)$ & 0,01 \\
\hline ombros & idade $30-39$ anos $^{(\bullet)}$ & $2,8(1,1-7,2)$ & 0,02 \\
\hline torácica & ausência de filhos ${ }^{(\bullet)}$ & $2,5(1,1-5,5)$ & 0,01 \\
\hline punhos e mãos & não tem união estável(•) & $2,0(1,0-3,9)$ & 0,04 \\
\hline
\end{tabular}

Na análise multivariada, constatou-se que a região cervical $(\mathrm{OR}=6,2$, IC à 95\% = 1,4 - 26,7) apresentou associação significativa para a idade menor que 30 anos. A presença de dor osteomuscular na região dos ombros (OR $=2,8$, IC à $95 \%=1,1-7,2$ ), apresentou associação estatisticamente significativa para os sujeitos na faixa etária entre 30 e 39 anos. A região torácica apresentou associação ligados a vínculos empregatícios, normas e locais diferentes, o que, possivelmente, acarreta um aumento do desgaste físico e mental devido, respectivamente, à locomoção e às leis diferenciadas. A baixa remuneração e a instabilidade podem explicar o trabalho em vários locais.

Quanto ao número de alunos por classe, 44,5\% dos professores relataram ministrar aulas em salas com um número 
igual ou maior que 35 alunos. De acordo com a nova lei, LDB (Art 25) o número ideal de alunos por sala de aula é responsabilidade do respectivo sistema de ensino, dependendo das características regionais e locais ${ }^{14}$. Considerando todas as atividades inerentes ao trabalho do educador, o número de alunos por classe sugere uma sobrecarga tanto no aspecto físico como mental. Importante observar que foi relatada a lousa como o material mais utilizado durante a prática da profissão. Seu uso, pela postura adotada em sua prática, parece ser um fator fatigante para a estrutura musculoesquelética favorecendo o surgimento de sintomas em determinadas regiões corporais. O tempo médio de atuação profissional da presente pesquisa foi de 16,4 anos com uma carga horária média semanal de 34,6 horas. Segundo o Art. $67 / \mathrm{V}$, o horário para preparar aulas, corrigir provas e realizar estudos, deveria estar incluso no total das horas realizadas semanalmente ${ }^{14}$.

Pode-se supor que a carga horária de trabalho desses trabalhadores, na realidade, é bem maior, o que eleva o período de exposição a diversos fatores de risco. Cerca de 5,7\% da amostra referiram realizar outra atividade ocupacional remunerada diferente do magistério com um tempo médio de 34,4 horas semanais. Esse fato parece indicar certo grau de insatisfação, financeira ou profissional com a atividade docente. Mais da metade da amostra possui de 4 a 6 saláriosmínimos como rendimento médio pessoal. De acordo com a LDB (Art. 67) o salário do professor segue de acordo com o piso salarial profissional ${ }^{14}$. Durante a realização da presente pesquisa, os professores queixaram informalmente que consideram seus salários muito defasados, que não eram justos pelo desgaste diário que sofriam.

Os professores apresentaram uma alta prevalência de sintomas musculoesqueléticos, nos últimos 12 meses assim como nos últimos 7 dias. As regiões mais afetadas foram lombar, torácica, cervical, ombros, punhos e mãos. Como conseqüência às queixas relatadas, os professores pesquisados apresentaram ocorrência considerável de impedimento na realização de atividades normais e procura por algum profissional da área da saúde. Esses dados sugerem que os sintomas osteomusculares representam um risco ocupacional para os professores. A ausência de filhos e tempo menor de atuação profissional foram os fatores que apresentaram associação significativa para a presença de sintomas musculoesqueléticos independentemente da região corporal afetada. Observou-se também que quanto menor o tempo de atuação profissional maior a chance do trabalhador apresentar sintoma osteomuscular. Os dados encontrados são difíceis de serem explicados. Espera-se que mulheres com filhos tenham mais responsabilidades, o que acarretaria uma dupla jornada de trabalho, significando, desta maneira, uma maior sobrecarga física. Uma suposição é que por não terem filhos, esses professores estão aumentando suas cargas de atividades profissionais.
Quanto ao tempo de atuação profissional, sugere-se que muitos ainda podem estar passando por uma fase de adaptação em relação às suas atividades ocupacionais. A relação inversa à esperada entre tempo de exposição e sintomas também pode ser decorrente de viés de sobrevivência típico do desenho transversal, sugerindo afastamentos ou mudanças de trabalho daqueles com sintomas persistentes ou mais graves. A região torácica apresentou associação significativa com a presença de dor osteomuscular e ausência de filhos. A dor em região de punhos e mãos apresentou associação entre professores que lecionam em mais de uma rede de ensino. Como já foram citados, anteriormente, estes fatos são de difícil explicação. É possível que o fato da locomoção de um local para o outro, diferentes métodos de ensino e pressão dos responsáveis pelas instituições, levam a um estresse físico e psicológico que afetam conseqüentemente todo o sistema osteomuscular e a qualidade de vida desses indivíduos. Silvany Neto et al. ${ }^{12}$, em estudo sobre condições de trabalho do professor, acreditam que a inserção em mais de uma escola resulta em deslocamentos mais freqüentes e maior acúmulo de tarefas, acarretando sobrecarga de trabalho, podendo causar o surgimento de sintomas osteomusculares. A idade menor que 30 anos apresentou diferença significativa quanto a presença de dor osteomuscular na região cervical. Isto pode ser explicado pelo fato dos professores, nesta faixa etária, estarem iniciando suas atividades profissionais o que seria um fator estressante para estes trabalhadores. Finsen et al. ${ }^{15}$, em pesquisa com dentistas, encontraram que profissionais mais velhos apresentam menos dor em determinadas regiões corporais do que os mais jovens, o que pode ser explicado por um nível maior de estresse nos trabalhadores ingressantes no mercado de trabalho. Com relação à região dos ombros, verificou-se associação de dor na faixa de idade entre 30 e 39 anos. Esses trabalhadores, nesta fase da vida, estão em um nível altamente produtivo o que aumentaria ainda mais a exposição a fatores de risco. Zwart et al. ${ }^{16}$ observaram que trabalhadores de meia idade e jovens desenvolvem sintomas musculoesqueléticos em virtude da elevada demanda de trabalho, pois, assumem um número maior de responsabilidades e tarefas. A idade é usualmente um fator de risco para o desenvolvimento de distúrbios osteomusculares. Os dados da presente pesquisa podem ser explicados pelo fato de que aqueles com mais idade e com problemas de saúde podem ter abandonado a profissão ou estarem exercendo atividades administrativas ou afastados por problemas mais sérios de saúde. Não ter um companheiro fixo apresentou relação significativa para a presença de dor osteomuscular na região de punhos e mãos. Analisando que a maior parte dos participantes são mulheres, não ter um companheiro fixo pode significar assumir maiores responsabilidades principalmente econômicas. Resumindo, os dados sugerem que professores mais novos, que não possuem uma união estável, sem filhos e com um tempo 
menor de atuação profissional estão mais sujeitos ao aparecimento de sintomas osteomusculares.

Ao analisar os fatores de risco de uma forma geral, encontraram-se fatores pessoais e ocupacionais. Verificouse também que os achados são controversos, principalmente quando os fatores são avaliados por área corporal separadamente. Muitos resultados são difíceis de explicar e podem ser decorrentes do desenho metodológico adotado para este estudo. Tais achados podem ser esperados, uma vez que os sintomas osteomusculares têm origem multifatorial e na situação real de trabalho vários fatores podem estar influenciando sua ocorrência simultaneamente.

É importante destacar que o objetivo deste estudo foi avaliar as condições de vida e de trabalho dos professores do Ensino Fundamental, não se pretendendo avaliar fatores causais da ocorrência de sintomas musculoesqueléticos. Porém ao se estudar a problemática dos sintomas osteomusculares entre os professores, optou-se também por discutir outros aspectos da vida e trabalho desse grupo ocupacional. A avaliação dos fatores de risco relacionados aos distúrbios osteomusculares é um desafio, em virtude, particularmente dos inúmeros aspectos envolvidos na problemática do trabalho. Dentre os aspectos destacam-se os psicossociais que não foram investigados nesta pesquisa. Outra questão, típica de estudo do tipo transversal, é a inabilidade em determinar o período de tempo a que os sujeitos foram expostos aos fatores de risco, além da dificuldade de relacionar as causas do aparecimento dos sintomas musculoesqueléticos.

\section{CONCLUSÃO}

Os professores do presente estudo apresentaram elevada ocorrência de sintomas musculoesqueléticos, sendo que as regiões mais afetadas foram a coluna lombar, a torácica, a cervical, os ombros e os punhos e mãos. A grande procura por auxílio de algum profissional da área da saúde e a influência na execução das atividades cotidianas reforçam que os sintomas osteomuculares representam um problema para esta categoria profissional.

Os resultados também mostraram que vários fatores individuais e ocupacionais podem estar relacionados com sintomas musculoesqueléticos nas diferentes regiões corporais. Verificou-se que professores mais novos, que não possuem uma união estável, sem filhos e com um tempo menor de atuação profissional estão mais sujeitos ao aparecimento de sintomas osteomusculares.

Os resultados da presente pesquisa confirmam a necessidade de novos estudos quanto aos aspectos psicossociais, ergonômicos e organizacionais do trabalho docente.

\section{REFERÊNCIASBIBLIOGRÁFICAS}

1. Punnett L, Wegman DH. Work-related musculoskeletal disorders: the epidemiologic evidence and the debate. J Electromyogr Kinesiol 2004; 14: 13-23.

2. Lee P. The economic impact of musculoskeletal disorders. Qual Life Res 1994; 3 (1): 85-91.

3. Barros ENC, Alexandre NMC. Cross-cultural adaptation of the Nordic musculoskeletal questionnaire. Int Nurs Ver 2003; 50 (2): 101-08.

4. National Institute For Occupational Safet And Health (Niosh). Musculoskeletal disorders and work place factors. Cincinnati: Bernard EP (Org); 1997.

5. Yeng LT, Teixeira MJ, Romano MA, Barboza HFG. Distúrbios osteomusculares relacionados com o trabalho. In: Lianza, S. (Org.). Medicina de Reabilitação. 3. ed., Rio de Janeiro: Guanabara Koogan; 2001. p. 420-31.

6. Brasil. Ministério da Saúde. Doenças relacionadas ao trabalho: manual de procedimentos para os serviços de saúde. Brasília, DF; 2001.

7. Marras WS. State-of-the-art research perspectives on musculoskeletal disorder causation and control: the need for an intergraded understanding of risk. J Electromyogr Kinesiol 2004; 14: $1-5$.

8. Melhorn JM, Wilkinson L, Riggs JD. Management of musculoskeletal pain in the workplace. J Occup Environ Med 2001; 43 (2): 83-93.

9. Devereux JJ, Vlachonikolis IG, Buckle PW. Epidemiological study to investigate potential interaction between physical and psychosocial factors at work that may increase the risk of symptoms of musculoskeletal disorders of the neck and upper limb. Occup Environ Med 2002; 59: 269-77.

10. Alexander DL. School employees: the forgotten municipal workers. Occup Med 2001; 16 (1): 65-78.

11. English CJ, Maclaren WM, Court-Brown C, Hughes SP, Porter RW, Wallace WA, et al. Relations between upper limb soft tissue disorders and repetitive moments at work. Am J lnd Med 1995; 27 (1): 75-90.

12. Silvany Neto AM, Araújo TM, Dutra FRD, Azi GR, Alves RL, Kavalkievicz $C$ et al. Condições e trabalho e saúde de professores da rede particular de ensino de Salvador, Bahia. Rev Baiana Saúde Publ 2000; 24 (1/2): 42-56.

13. Homer DW, Lemeshow SL. Applied Logistic Regression. New York: John Wiley \& Sons; 1989.

14. Castro MLO. A educação na Constituição de 1988 e a LDB: Lei de diretrizes e bases da educação nacional. Brasília: André Quicé; 1998. p. 278.

15. Finsen L, Christensen H, Bakke M. Musculoskeletal disorders among dentists and variation in dental work. Appl Ergon 1998; 29 (2): 119-25.

16. Zwart BCH, Broersen JPJ, Frings-Dresen MHW, van Dijk FJH. Repeated survey on changes in musculoskeletal complaints relative to age and work demands. Occup Environ Med 1997; 54: 793-99. 